\title{
Clinico histopathological evaluation of abnormal uterine bleeding in women of reproductive and perimenopausal age group
}

\author{
Ela Jha $^{1 *}$, Arun Kumar Jha ${ }^{2}$, Annie Samuel ${ }^{1}$
}

\begin{abstract}
${ }^{1}$ Department of Obstetrics and Gynecology, Mahatma Gandhi Memorial Medical College and Hospital (MGM MCH), Jamshedpur, Jharkhand, India

${ }^{2}$ Department of Pathology, Mahatma Gandhi Memorial Medical College and Hospital (MGM MCH), Jamshedpur, Jharkhand, India
\end{abstract}

Received: 15 July 2019

Revised: 15 October 2019

Accepted: 05 November 2019

\section{*Correspondence:}

Dr. Ela Jha,

E-mail: jhaela10@gmail.com

Copyright: (C) the author(s), publisher and licensee Medip Academy. This is an open-access article distributed under the terms of the Creative Commons Attribution Non-Commercial License, which permits unrestricted non-commercial use, distribution, and reproduction in any medium, provided the original work is properly cited.

\section{ABSTRACT}

Background: Abnormal uterine bleeding constitutes a significant proportion of cases attending gynaecology outpatient department. It affects woman's physical, emotional, social and maternal well-being, and hence it demands adequate management. It is a multifactorial entity; presented in various patterns, signs and symptoms. The PALM COEIN classification is the most recent method of categorizing AUB (abnormal uterine bleeding) based on structural and non-structural causes. The treatment of AUB depends on age, parity, symptom severity, investigation findings and cause. Various invasive and non-invasive investigations including USG, endometrial biopsy and hysteroscopy helps find different causes. Whatever be the etiology endometrium gets affected; hence AUB is likely managed through hormonal preparations, LNG-IUS, endometrium ablation/resection and ultimately hysterectomy as the last resort.

Methods: A retrospective study comprising 216 patients in the age group of 30-50 years with complaints of AUB were recorded as per a structured proforma at department of obstetrics and gynaecology, MGM MCH over a period of one year (January 2018-19). The results of investigations, ultrasound scans, endometrial biopsy and histopathology of hysterectomised specimens were correlated. The endometrial biopsy and histopathology of the specimens was done at department of pathology, MGM MCH.

Results: The most common age group showing AUB lies under 35-40 years $(40.2 \%)$ and $40-45$ years $(33.7 \%)$. Menorrhagia was found to be the most common symptom (66.2\%). As per PALM COEIN classification, the most common type in our study was of AUB-L (33.7\%) and the associated histopathological pattern was of secretory type $(50.4 \%)$.

Conclusions: The features and patterns of AUB differ according to the age of patient, affecting mostly women in perimenopausal and late reproductive age group. There are various modalities for its diagnosis and management and PALM COEIN classification helps better understand the disease etiology.

Keywords: Abnormal uterine bleeding, Endometrial biopsy, Hysteroscopy, Perimenopausal, Palm coein

\section{INTRODUCTION}

AUB is one of the most common gynaecological complains experienced by women. It is more prevalent in perimenopausal age group. ${ }^{1}$ In 2001, Stages of Reproductive Ageing Workshop defined "Perimenopause as the beginning with menopausal transition and ending 12 months after the last menstrual period". It lasts for 2-5 
years and is associated with hormonal and systemic changes accounting for a wide spectrum of menstrual abnormalities.

AUB leads to almost two-thirds of all hysterectomies done across the world and is hence a leading cause of morbidity and mortality. The prevalence of AUB in gyanec OPD is about $10-15 \%$, with an incidence of $17.9 \%$ in India. The incidence increases from $6.4 \%$ in $30-$ 35 years to $18 \%$ in $45-50$ years. It usually follows a chronic course, but if it becomes acute, the patient may land up in hypovolemic shock and cardiac failure.

The most common cause of AUB is the disturbance in the hypothalamo-pituitary-ovarian (HPO) axis. It leads to reduced level of progesterone and alteration in the ratio of PGE2 and PGF2 alpha. There is hyperfunctioning of tissue plasminogen activator, a fibrinolytic enzyme, leading to prolonged and heavy bleeding. AUB can be ovulatory or non-ovulatory and can occur in any age group. ${ }^{2}$ The PALM component of the classification deals with the structural causes, while the COEIN component deals with the non-structural causes. ${ }^{3}$

For the evaluation of AUB cases, a detailed history with regards to age, parity, menstrual pattern, recent pregnancy events, IUCD/OCP, white discharge has to be taken. Pregnancy has to be excluded first and foremost. Routine blood investigations, PAP smear, thyroid and prolactin estimation is also necessary. Imaging includes ultrasound both TAS and TVS, as each of them have their own merits and demerits. Saline infusion sonography detects endometrial polyps and submucosal fibroids. Hysteroscopic guided biopsy is the gold standard in the evaluation of AUB. D and C along with endometrial biopsy is both diagnostic and therapeutic. Malignancy has to be ruled out, especially in the perimenopausal age group.

Treatment is tailored according to every patient. Medical management includes hormonal drugs and injectables, along with anti-fibrinolytics and hematinics. Blood transfusion also becomes necessary in many cases. LNGIUS is very effective and also provide contraceptive and hormone replacement benefits, provided that the shape of the endometrial cavity is not distorted. Endometrial resection and ablation is done in non-responsive cases, when fertility is no longer desired, but the patient wants to preserve the uterus. Trans-cervical resection of endometrium (TCRE), roller ball, microwave, laser and thermal ablation are various modalities. In cases of recurrence or failure, or when such sophisticated facilities are not available, hysterectomy becomes the last resort. ${ }^{4}$

Objective of this study was clinico histopathological evaluation of the cases of AUB, with respect to PALM COEIN classification in women of reproductive and perimenopausal age group.

\section{METHODS}

A cohort of 216 women, with complains of abnormal uterine bleeding, in the age group of 30 to 50 years and above, were evaluated and followed up in the out patient department of obstetrics and gynaecology, MGM MCH, a tertiary care hospital in Jamshedpur, East Singhbhum, Jharkhand, India.

A retrospective study was carried out over a period of one year, from January 2018 to January 2019. The history taking of the patients was done with regards to age, parity, menstrual history, duration of symptoms and recurrence if any, contraceptive history, obstetric history, history suggestive of PID. After taking informed consent, a thorough general, systemic and gynaecological evaluation of the patients was done. The findings of blood investigations, sonography, histopathology of biopsy specimens and hysterectomised specimens were recorded. In the subset of patients who underwent hysterectomy, biopsy and histopathology reports were evaluated and compared.

Before starting the workup, pregnancy was excluded using urine beta HCG. After this, the structural etiologies of the PALM group were excluded using transabdominal or transvaginal USG. Endometrial biopsy was done in patients above 40 years, and those with high risk factors for endometrial carcinoma such as nulliparity, PCOD, diabetes, obesity, family history of endometrial cancer, and when medical management failed to stop bleeding.

After the structural causes were excluded, the nonstructural origin of AUB is suspected, which includes the following etiologies: due to coagulopathy (AUB-C), ovulatory disorder (AUB-O), primary endometrial pathology (AUB-E), iatrogenic causes (AUB-I), and causes of AUB not yet identified (AUB-N).

\section{Inclusion criteria}

- Women in the age group of 30-50 years and above, with complains of abnormal uterine bleeding.

\section{Exclusion criteria}

- Women who were pregnant, or having an abortion

- Women who refused endometrial biopsy.

\section{Sample size}

The formula to estimate sample size for a qualitative variable is as follows

$$
\begin{aligned}
& \begin{array}{l}
\text { Sample size }(S)=\underline{Z}_{(1-\text { alpha/2 })} \\
d^{2}
\end{array} \underline{p(1-p)} \\
& Z_{1-\text { alpha/2 }}=\text { Is standard normal variant, at } 5 \% \text { type I error, } \\
& \text { when } p \text { value is }<0.05 \text {, is equals to } 1.96
\end{aligned}
$$


$\mathrm{p}=$ Expected proportion in population based on previous studies or pilot studies. It is equal to $17.9 \%$ with respect to previous AUB studies.

$\mathrm{d}=$ Absolute error, which has been kept as 5\% type I error.

Sample size $(S)=\underline{1.96 \times 1.96 \times 0.17(1-0.17)}$

$$
0.05 \times 0.05
$$

$$
S=216
$$

\section{RESULTS}

In the present study, the maximum incidence of AUB is seen in reproductive and perimenopausal age groups between $35-40$ years $(40.2 \%)$ and $40-45$ years $(33.7 \%)$. This is followed by $18 \%$ patients in the age group of $45-$ 50 years, $6.4 \%$ in $30-35$ years and $1.3 \%$ in > 50 years (Figure 1).

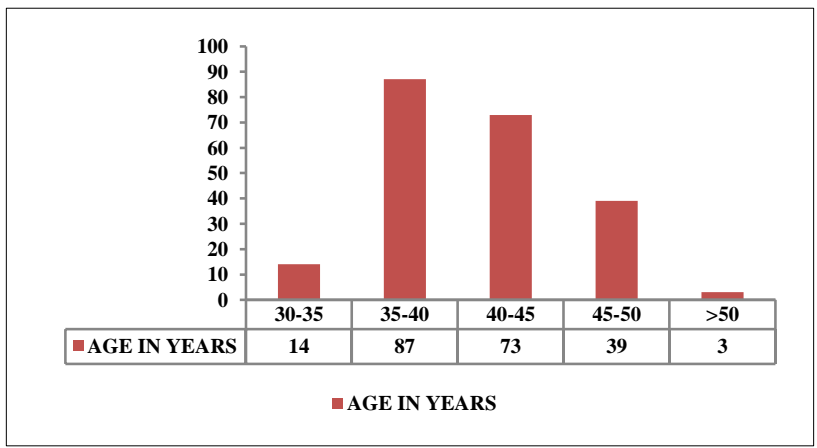

Figure 1: Age distribution of patients.

The parity status of the patients has a direct correlation with the incidence of AUB. In multiparous females the incidence of AUB is $41.2 \%$ and $21.7 \%$ in grand multipara. The incidence falls to $28.7 \%$ in primipara and $8.3 \%$ in nulliparous females (Figure 2).

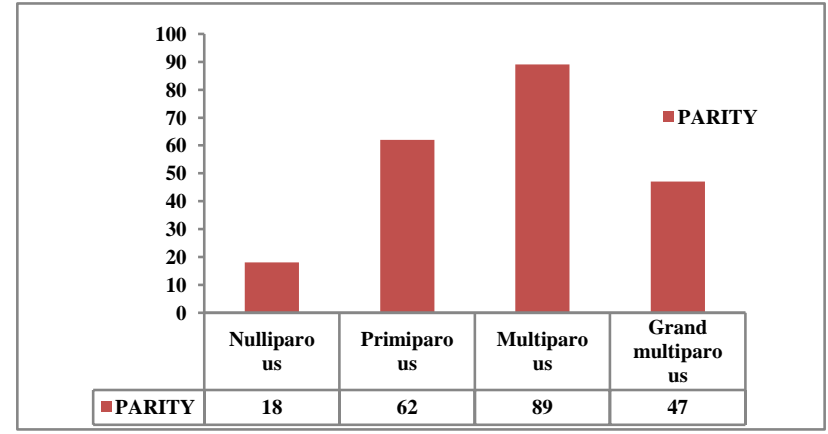

Figure 2: Parity distribution of patients.

Among various patterns of AUB, menorrhagia is most commonly seen $(66.2 \%)$, followed by polymenorrhea $(10.1 \%)$, and polymenorrhagia $(12.1 \%)$. Less common patterns are metrorrhagia $(4.6 \%)$, menometrorrhagia $(3.7 \%)$ and hypomenorrhea (3.2\%) (Table 1).
Table 1: Patterns of AUB.

\begin{tabular}{|lll|}
\hline Patterns of AUB & Number of cases & $\%$ \\
\hline Menorrhagia & 143 & 66.2 \\
\hline Polymenorrhea & 22 & 10.1 \\
\hline Polymenorrhagia & 26 & 12.1 \\
\hline Metrorrhagia & 10 & 4.6 \\
\hline Menometrorrhagia & 8 & 3.7 \\
\hline Hypomenorrhea & 7 & 3.2 \\
\hline
\end{tabular}

In the present study, it is observed that chronic type of heavy menstrual bleeding is the most common type of AUB (64.3\%). Acute type of AUB is seen in $14.8 \%$ of cases, while acute on chronic cases constitute $(9.7 \%)$. Intermenstrual type, although less common, but still found in $(17.1 \%)$ cases. Cases of AUB in postmenopausal age group are (1.3\%) (Table 2$)$.

Table 2: Types of AUB.

\begin{tabular}{|lll|}
\hline Types of AUB & Number of cases & $\%$ \\
\hline Acute & 16 & 14.8 \\
\hline Chronic & 139 & 64.3 \\
\hline Acute on chronic & 21 & 9.7 \\
\hline Intermenstrual & 37 & 17.1 \\
\hline Post-menopausal & 3 & 1.3 \\
\hline
\end{tabular}

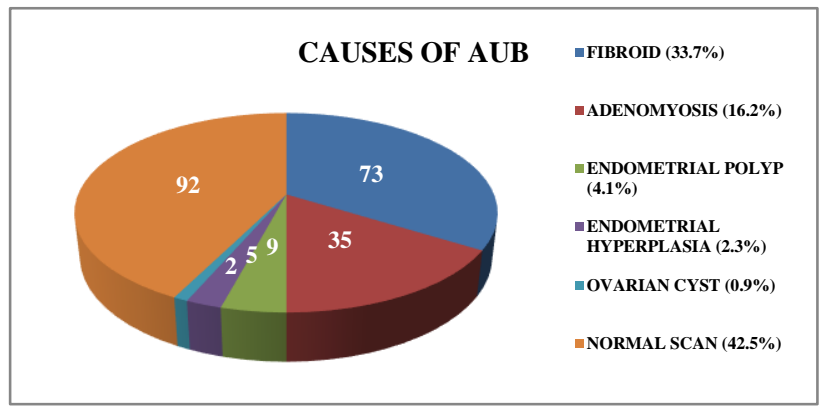

Figure 3: Structural causes of AUB according to ultrasound.

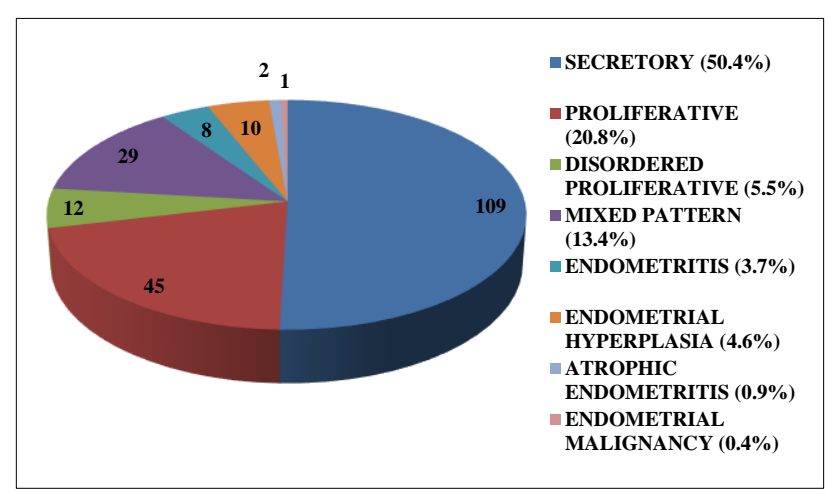

Figure 4: Histopathological patterns of AUB.

Among the various organic causes of AUB, fibroids $(33.7 \%)$ and adenomyosis $(16.2 \%)$ constitute maximum number of cases. A major proportion of subjects had no 
detectable pathology on USG scan $(42.5 \%)$. Endometrial polyps $(4.1 \%)$, endometrial hyperplasia $(2.3 \%)$ and ovarian cysts $(0.9 \%)$ were other anomalies found during USG imaging of the subjects (Figure 3 ).

On histopathology, secretory endometrium was found in $(50.4 \%)$ cases, proliferative type in $(20.8 \%)$, disordered proliferative in $(5.5 \%)$, mixed pattern in $(13.4 \%)$, endometritis in $(3.7 \%)$ cases. Endometrial hyperplasia in (4.6\%) cases, atrophic endometritis in (0.9\%) and endometrial malignancy in $(0.4 \%)$ cases (Figure 4$)$.

\section{DISCUSSION}

Abnormal uterine bleeding is defined as any bleeding of uterine origin which does not fulfil the criteria of normal duration, volume, regularity or frequency. It has various patterns and a multifactorial etiology; which can be structural or non-structural in nature. Hence to create a universally accepted nomenclature of AUB, FIGO and ACOG has given the PALM- COEIN classification. Dysfunctional uterine bleeding (DUB) is a type of AUB when all the organic causes have been excluded.

In the present study, the maximum incidence of AUB is seen in reproductive and perimenopausal age groups between $35-40$ years $(40.2 \%)$ and $40-45$ years $(33.7 \%)$. This is followed by $18 \%$ patients in the age group of 45 50 years, $6.4 \%$ in $30-35$ years and $1.3 \%$ in > 50 years. Similar results have been obtained in the studies of Yusuf et al and Muzaffar et al on endometrium. 5,6 In the perimenopausal age group, there is a disturbance in the HPO axis leading to anovulatory bleeding in approximately $80 \%$ cases, while in the reproductive age group organic causes such as fibroids and polyps are found more commonly (Figure 1).

The parity status of the patients has a direct correlation with the incidence of AUB. In multiparous females the incidence of AUB is $41.2 \%$ and $21.7 \%$ in grand multipara. The incidence falls to $28.7 \%$ in primipara and $8.3 \%$ in nulliparous females. Similar incidence of parity is seen in the studies of Mehrotra VG et al, Pilli GS et al, Archana B et al (Figure 2). ${ }^{7,9}$

Heavy menopausal bleeding (HMB) is the most common type of AUB (66.2\%) as it is associated with most of the structural as well as non-structural causes of AUB. polymenorrhea $(10.1 \%)$ and polymenorrhagia $(12.1 \%)$ are types of ovular bleeding when there occurs hyperstimulation of follicular growth by FSH, resulting in shortening of the follicular phase. Metrorrhagia (4.6\%) and menometrorrhagia $(3.7 \%)$ have specific etiologies and carcinomas of the cervix and endometrium have to be excluded as a must in every such case. The causes of hypomenorrhea are mainly endocrinal such as thyroid dysfunction, hyperprolactinemia, OCP use. It can also be due to uterine synechiae or tubercular endometritis. The findings of the present study also correlated with the findings of studies done by Katke RD et al (Table 1). ${ }^{10}$
In the present study, it is observed that chronic type of heavy menstrual bleeding is the most common type of AUB (64.3\%). An ovular bleeding is mostly heavy, due to anovulation endometrium is under the influence of unopposed estrogen and there is no growth limiting progesterone, after a variable period of amenorrhea. When the endometrial shedding takes place due to lack of stromal and vascular support, the bleeding is heavy and prolonged.

Fibroids is another important reason for chronic type of HMB, submucous variety of fibroids are most symptom producing, hence classified separately under PALM COEIN as (L- SM). Intramural fibroids are also a cause of chronic type of AUB. Fibroids cause an increase in the endometrial surface area, uterine enlargement, pelvic congestion and increased uterine vascularity, these were the reasons implicated for HMB in fibroids. But recent theories suggest chromosomal and genetic variations causing a progenitor myocyte to be responsible for inducing various angiogenic changes, growth factor upregulation and changes in coagulation in fibroids. Cases of adenomyosis also lead to chronic bleeding in AUB. The patient becomes anaemic and if it is uncared for over a long period of time, may result in severe anaemia with or without cardiac failure.

Acute type of AUB is seen in $14.8 \%$ of cases, while acute on chronic cases constitute (9.7\%). Anovulatory DUB which occurs as in cystic glandular hyperplasia and PCOS can become acute at times requiring urgent intervention and support. Ovulatory DUB causing polymenorrhea and polymenorrhagia following childbirth or abortion and in cases of PID can present as acute type of DUB. Endometrial polyps and coagulopathies are important causes of acute on chronic AUB (9.7\%). In cases of intermenstrual bleeding $(17.1 \%)$, high grades of CIN, carcinoma in situ and invasive cervical carcinoma has to be ruled out as a must. Mucous polyps, vascular ectopy of cervix, IUCD use and decubitus ulcer are other local causes of intermenstrual bleeding.

Post-menopausal bleeding is seen in 3 out of 10 menopausal patients taken in the study. Even slightest amount of PMB has to be considered for endometrial carcinoma, until unless proven otherwise. Local and systemic examination along with endometrial biopsy and hysteroscopic evaluation is necessary. History of HRT, forgotten pessary, IUCD also has to be enquired for (Table 2).

Among the various organic causes of AUB, fibroids $(33.7 \%)$ and adenomyosis $(16.2 \%)$ constitute maximum number of cases. A major proportion of subjects had no detectable pathology on USG scan $(42.5 \%)$. Endometrial polyps $(4.1 \%)$, endometrial hyperplasia $(2.3 \%)$ and ovarian cysts $(0.9 \%)$ were other anomalies found during USG imaging of the subjects (Figure 3). Similar results were found in studies done by Mary Gayle et al. ${ }^{11}$ 
On histopathological evaluation, 50.4\% specimens had secretory type of endometrium and $20.8 \%$ had proliferative type. Disordered type of proliferative epithelium $(5.5 \%)$ and endometrial hyperplasia (4.6\%) are the precursor changes for endometrial malignancy found in $0.4 \%$ cases. The etiology of mixed pattern $(13.4 \%)$ of endometrial changes is because of irregular shedding of endometrium due to incomplete atrophy of corpus luteum and hence incomplete withdrawal of $\mathrm{LH}$ even on day $26^{\text {th }}$ of the cycle. $3.7 \%$ specimens showed features of endometritis, mostly there is no apparent etiology, but organisms such as Chlamydia, Neisseria, group B streptococcus, mycoplasma, and tuberculosis are responsible for inflammation of endometrium. Atrophic changes $(0.9 \%)$ in the endometrium are found after menopause and in perimenopausal patients due to the deficiency of estrogen. Katke RD et al.10 showed proliferative endometrium in $46.9 \%$ cases, hyperplastic in $6 \%$, irregular shedding in $1.5 \%$ and atrophic in $1.6 \%$ cases of AUB in perimenopausal women. Kumar S et al, showed proliferative endometrium in $36 \%$, secretory in $24 \%$, hyperplastic in $16 \%$ and atrophic in $14 \%$ cases (Figure 4). ${ }^{12}$

\section{CONCLUSION}

AUB is an entity which encompasses a wide spectrum of symptoms and presentations, taking into consideration various factors. Every case of AUB has its own characteristic findings on USG, endometrial biopsy and histopathology; hence a generalized or a single modality of treatment cannot be applicable for every patient. Therefore, it is of utmost importance to first analyse the etiology of abnormal bleeding in a particular case, through history taking, examination, imaging and tissue diagnosis and then formulating the appropriate line of management. The ultimate aim is to improve the quality of life of the women.

Funding: No funding sources Conflict of interest: None declared

Ethical approval: The study was approved by the Institutional Ethics Committee

\section{REFERENCES}

1. Kjerulff KH, Erickson BA, Langenberg PW. Chronic gynecological conditions reported by US women: findings from the National Health Interview Survey, 1984 to 1992. Am J Public Health. 1996;86(2):195-9.

2. Fraser IS, Critchley HO, Broder M, Munro MG. The FIGO recommendations terminologies and definitions for normal and abnormal uterine bleeding. Semin Reprod Med. 2011;29(5):383-90.
3. Munro MG, Critchley HO, Broder MS, Fraser IS. FIGO classification system (PALM-COEIN) for causes of abnormal uterine bleeding in nongravid women of reproductive age. Int J Gynaecol Obstet. 2011;113(1):3-13.

4. Farquhar C, Ekeroma A, Furness S, Arroll B. A systematic review of transvaginal sonography, sonohysterography and hysteroscopy for the investigation of abnormal uterine bleeding in premenopausal women. Acta Obstet Gynecol Scand. 2003;82:493-504.

5. Yusuf, Ghanbarzadeh N, Haghighi F, Semnani FN, Semnani AN, Sa'adatpoor E. Pathological patterns of endometrial curettage samples in women referred with abnormal uterine bleeding: A descriptive study. J Surg Trauma. 2015;3(3-4):39-5.

6. Muzaffar M, Akhtar KAK, Yasmin S, Rahman M, Iqbal W, Khan MA. Menstrual irregularities with excessive blood loss: A clinico-pathological correlation. J Pak Med Assoc. 2005;55:486-9.

7. Mehrotra VG, Doraiswami S, Johnson T, Rao S, Rajkumar A, Vijayaraghavan J, et al. Study of endometrial pathology in abnormal uterine bleeding. J Obstet Gynecol India. 2011;61(4):426-30.

8. Pilli GS, Bhatta S, Sinha AK. Histopathological study of endometrium in abnormal uterine bleeding. J Pathol Nepal. 2012;2(4):297.

9. Archana B, Gopalan U, Rajendiran S, Karnaboopathy R. Study of endometrial histopathology in women with abnormal uterine bleeding. Int J Reprod Contracept Obstet Gynecol. 2017;6(3):824-8.

10. Katke RD, Damle RP, Dravid NV, Suryawanshi KH, Gadre AS, Bagale PS, et al. Clinicopathological spectrum of endometrial changes in perimenopausal and menopausal uterine bleeding. J Clin Diagnos Res. 2013;7(12):2774-6.

11. Sweet MG, Schmidt-Dalton TA, Weiss PM. Evaluation and management of abnormal uterine bleeding in premenopausal women. Am Fam Physician. 2012;85(1):35-43.

12. Kumar S, Farquhar CM, Lethaby A, Sowter M, Verry J, Baranyai J. An evaluation of risk factors for endometrial hyperplasia in premenopausal women with abnormal menstrual bleeding. Am J Obstet Gynecol. 1999;181:525-9.

Cite this article as: Jha E, Jha AK, Samuel A. Clinico histopathological evaluation of abnormal uterine bleeding in women of reproductive and perimenopausal age group. Int J Reprod Contracept Obstet Gynecol 2019;8:4736-40. 